\title{
Heat shock protein 70 downregulation inhibits proliferation, migration and tumorigenicity in hepatocellular carcinoma cells
}

\author{
$\mathrm{JU} \mathrm{XIONG}^{1^{*}}$, XUE-MEI JIANG ${ }^{2 *}$, SHAN-SHAN MAO ${ }^{3}$, XIANG-NAN YU $^{2}$ and XIAO-XI HUANG ${ }^{2}$ \\ ${ }^{1}$ Department of General Surgery, People's Hospital of Xinjiang Uygur Autonomous Region, Urumqi, Xinjiang 830001; \\ Departments of ${ }^{2}$ Gastroenterology and ${ }^{3}$ Oncology, Haikou People's Hospital, Haikou, Hainan 570028, P.R. China
}

Received October 14, 2015; Accepted May 11, 2017

DOI: $10.3892 / \mathrm{ol} .2017 .6531$

\begin{abstract}
The overexpression of heat shock protein 70 (HSP70), a major stress-inducible heat shock protein, has been identified to enhance the proliferation, survival, invasion and metastasis of diverse types of human cancer. However, its role in hepatocellular carcinoma (HCC) remains poorly understood. The present study demonstrated that HSP70 expression was higher in tested HCC cell lines, compared with the normal hepatocyte LO2, and the suppression of HSP70 significantly inhibited the proliferation of SMMC-7721 and Hep3B cells. The growth inhibitory effect was mediated by cell cycle arrest at the $G_{1} / S$ phase with reduced cyclin D1 and increased $p 27^{\mathrm{Kip} 1}$ expression. Furthermore, HSP70 knockdown significantly inhibited the migration and invasion abilities of HCC cells. In conclusion, HSP70 is a key regulator involved in the proliferation, migration and invasion of $\mathrm{HCC}$, and it may be used as a potential therapeutic target for HCC.
\end{abstract}

\section{Introduction}

Hepatocellular carcinoma (HCC) represents the third highest cause of cancer-associated mortality, and one of the most aggressive human malignancies worldwide (1). Screening of HCC using ultrasonography and measurement of the serum $\alpha$-fetoprotein level has allowed early detection, consequently increasing the survival of patients (2). However, the overall survival of patients with HCC following resection remains unsatisfactory due to recurrence and metastasis. Multiple

Correspondence to: Professor Xiao-Xi Huang, Department of Gastroenterology, Haikou People's Hospital, 43 Renmin Avenue, Meilan, Haikou, Hainan 570028, P.R. China

E-mail:shiabde@yahoo.com

*Contributed equally

Abbreviations: HCC, hepatocellular carcinoma; HSP, heat-shock protein

Key words: heat shock protein 70, liver cancer, proliferation, migration and invasion, cell cycle genetic and epigenetic alterations occur during the carcinogenesis and progression of HCC (3-5). The aggressiveness of this disease may be caused by the activation of oncogenes, the inactivation of tumor suppressor genes, and the deregulation of growth factors and their corresponding receptors $(6,7)$. However, the mechanism responsible for HCC progression remains elusive.

Molecular chaperones, a number of which are heat-shock proteins (HSPs), are often overexpressed in various types of cancer and have been suggested to be contributing factors in tumorigenesis (8). Several previous studies have demonstrated that aberrant expression of HSP70 members correlates with poor prognosis and resistance to therapy in malignant human tumors, including breast cancer, bladder cancer, melanoma and oral cancer (9-12). Conversely, there are also data that demonstrate that members of the HSP70 family are involved in antigen processing and presentation through binding to short peptides, thereby eliciting a strong antitumor immune response (13). Therefore, the involvement of HSP70 in such diverse roles may suggest its use in novel anticancer therapeutic approaches to a broad spectrum of tumor types. Although HSP70 serves a controversial role in various types of cancer, its biological effect in HCC remains unknown.

In the present study, the expression of HSP70 and its function were investigated in HCC cell lines, rendering it a potential target for therapeutic intervention in HCC.

\section{Materials and methods}

Cell culture and reagents. Human normal hepatocyte (L02) and HCC cell lines (Huh7, HepG2, Hep3B and SMMC-7721) were purchased from the Cell Bank of Type Culture Collection of Chinese Academy of Sciences (Shanghai, China). The cells were cultured in a petri-dish (Corning, Shanghai, China) containing Dulbecco's modified Eagle's medium (DMEM; Gibco; Thermo Fisher Scientific, Inc.; Waltham, MA, USA) supplemented with $10 \%$ fetal bovine serum (HyClone; GE Healthcare Life Sciences, Logan, UT, USA) and 1\% penicillin/streptomycin (Gibco; Thermo Fisher Scientific, Inc.), in an atmosphere containing $5 \% \mathrm{CO}_{2}$ at $37^{\circ} \mathrm{C}$.

RNA isolation and reverse transcription-quantitative polymerase chain reaction ( $R T-q P C R)$. Total RNA was extracted from cells using TRIzol ${ }^{\circledR}$ reagent (Invitrogen; Thermo Fisher 
Scientific, Inc.). The ultramicro spectrophotometer (Thermo Fisher Scientific, Inc.) was used to detect the purification and quantification of RNA. Complementary DNA (cDNA) was synthesized using PrimeScript ${ }^{\mathrm{TM}}$ RT reagent kit with gDNA Eraser (Takara Biotechnology Co., Ltd., Dalian, China). DNase (Takara Biotechnology Co., Ltd.) was used prior to the reverse transcription reaction. The conditions for reverse transcription reaction were as follows: $37^{\circ} \mathrm{C}$ for $15 \mathrm{~min}$ and then $85^{\circ} \mathrm{C}$ for $5 \mathrm{sec}$. RT-qPCR was performed using the Bio-Rad iCycler iQ Real-Time PCR system (Bio-Rad, Hercules, CA, USA) with the following primers: HSP70 forward, 5'-ACCTA CTCCG ACAAC CAA-3' and reverse, 5'-AGATG ACCTC TTGAC ACTTG-3'; GAPDH forward, 5'-CATGG CAAAT TCCAT GGCA-3' and reverse, 5'-TCTAG ACGGC AGGTC AGGTC CACC-3'. The PCR mixture was prepared using $\mathrm{SYBR}^{\circledR}$ Master Mix (Takara Biotechnology Co., Ltd.) in accordance with the protocol of the manufacturer. The conditions for PCR reaction were as follows, $95^{\circ} \mathrm{C}$ for $30 \mathrm{sec}$ for one cycle, and then $95^{\circ} \mathrm{C}$ for $5 \mathrm{sec}, 60^{\circ} \mathrm{C}$ for $30 \mathrm{sec}$ for 40 cycles. To ensure that only specific bands were produced, the melting curve was analyzed at the end of each PCR experiment. Expression levels of each mRNA were determined using the $2^{-\Delta \Delta C q}$ method using GAPDH as an endogenous control (14).

Western blotting. For western blotting, cells were lysed for $30 \mathrm{~min}$ on ice with radioimmunoprecipitation assay buffer containing phosphatase and protease inhibitors (Beyotime, Haimen, Jiangsu, China). The cell lysate was then centrifuged at $12,000 \mathrm{x} \mathrm{g}$ for $5 \mathrm{~min}$ at $4^{\circ} \mathrm{C}$. The supernatant was carefully collected following centrifugation. The protein concentrations were determined using a bicinchoninic acid protein assay (Pierce; Thermo Fisher Scientific, Inc.). The cell lysates (50 $\mu \mathrm{g}$ protein/lane) were separated by $10 \%$ SDS-PAGE and transferred to nitrocellulose membranes (HyClone; GE Healthcare Life Sciences). The membranes were blocked with $5 \%(\mathrm{v} / \mathrm{v})$ skim milk at room temperature for $1 \mathrm{~h}$, and then probed with the primary antibodies at $4^{\circ} \mathrm{C}$ overnight. Following washing with TBS/Tween-20 three times, the membranes were incubated with the horseradish peroxidase-conjugated secondary antibody (cat. no. 7076; Cell Signalling Technology, Danvers, MA, USA; dilution, 1:1,000;) at room temperature for $1 \mathrm{~h}$. A primary antibody against cyclin-dependent kinase inhibitor 1B (p27 $\left.{ }^{\mathrm{Kip} 1}\right)$ was purchased from BD Biosciences (cat. no. 610241; San Jose, CA, USA; dilution, 1:2,000). A primary antibody against Cyclin D1 was purchased from Santa Cruz Biotechnology Inc. (cat. no. sc-4074; Dallas, TX, USA; dilution, 1:1,000). Relative optical density of all bands was analyzed by GelPro Analyzer (V4.0; Media Cybernetics, Rockville, MD, USA).

Flow cytometry assay. Cell apoptosis was evaluated with the Annexin V-fluorescein isothiocyanate (FITC)/propidium iodide (PI) apoptosis detection kit (cat. no. 556547; BD Biosciences) according to the manufacturer's protocol. Pre-treated Hep3B or SMMC-7721 cells were stained with FITC-Annexin V and PI, and then evaluated for apoptosis using flow cytometry (FACSCalibur ${ }^{\mathrm{TM}}$; BD Biosciences), according to the manufacturer's protocol. Briefly, cells were harvested following the incubation period, washed twice in cold PBS, and centrifuged at $300 \times \mathrm{g}$ for $5 \mathrm{~min}$ at $4^{\circ} \mathrm{C}$.
A total of $\sim 1 \times 10^{6}$ cells were re-suspended in $500 \mu \mathrm{l} 1 \mathrm{X}$ Annexin-binding buffer and transferred to a sterile flow cytometry glass tube. A total of $5 \mu \mathrm{l}$ FITC-Annexin V and $10 \mu \mathrm{l}$ PI were added to each tube and incubated at room temperature for $5 \mathrm{~min}$ in the dark. Subsequent to incubation, samples were analyzed using the standard program of flow cytometry and analyzed using FlowJo V7.6.1 software (Tree Star, Inc., Ashland, OR, USA).

Cell proliferation assay. The viability of SMMC-7721 and Hep3B cells post-transfection was determined using a Cell Counting kit-8 (CCK-8; Dojindo Molecular Technologies, Inc., Kumamoto, Japan). Cells were seeded in 96-well culture plates at a density of $4 \times 10^{3}$ cells per well and transfected with the desired small interfering (si)RNA (GenePharma, Shanghai, China). Cellular transfection was performed using Lipofectamine 2000 (Invitrogen; Thermo Fisher Scientific, Inc.) according to the protocol. Subsequent to culturing for 1-5 days at $37^{\circ} \mathrm{C}$ with $5 \% \mathrm{CO}_{2}$, the supernatant was removed and cell growth was determined using a CCK-8 kit, according to the manufacturer's protocol. Absorbance was measured at $450 \mathrm{~nm}$ using a microplate reader.

Cell cycle analysis. Cells $\left(1 \times 10^{6}\right.$ cells/well) were seeded on 6 well plates (Corning Life Sciences, Shanghai, China) and cultured with DMEM medium at $37^{\circ} \mathrm{C}$ with $5 \% \mathrm{CO}_{2}$ for $24 \mathrm{~h}$, prior to being transfected with $100 \mathrm{nM}$ HSP70-siRNA or control siRNA (siCON) for $48 \mathrm{~h}$. For the flow cytometry, cells were trypsinized, pelleted via centrifugation at $1,000 \mathrm{x} \mathrm{g}$ for $5 \mathrm{~min}$ at $4^{\circ} \mathrm{C}$ and resuspended in $300 \mu \mathrm{l} 0.1 \%$ Triton $\mathrm{X}-100$ (Sigma-Aldrich; Merck KGaA, Darmstadt, Germany)/PBS. Cells were fixed with the cold $70 \%$ ethanol (Sangon Biotech Co., Ltd., Shanghai, China) at $4^{\circ} \mathrm{C}$ for $2 \mathrm{~h}$ and centrifuged at $1,000 \mathrm{x} \mathrm{g}$ for $5 \mathrm{~min}$ at $4^{\circ} \mathrm{C}$. Subsequent to washing twice in cold PBS and centrifugation at $1,000 \mathrm{x}$ g for $5 \mathrm{~min}$ at $4^{\circ} \mathrm{C}$, cells were treated with RNase Type I-A (Sigma-Aldrich; Merck KGaA) at $37^{\circ} \mathrm{C}$ for $15 \mathrm{~min}$ and stained with PI $(1 \mathrm{mg} / \mathrm{ml})$ at room temperature for $10 \mathrm{~min}$ in the dark. Cellular DNA content was determined using a FACSCalibur ${ }^{\mathrm{TM}}$ (BD Biosciences). Cell cycle phase distributions were analyzed by ModFit LT ${ }^{\mathrm{TM}}$ (v3.0; BD Biosciences) cell cycle analysis software.

Cell migration and invasion assay. For the migration assay, $1 \times 10^{4}$ Hep3B or SMMC-7721 cells were plated into 24-well Boyden chambers (Corning Incorporated, Corning, NY, USA) with an $8-\mu \mathrm{m}$ pore polycarbonate membrane. For the invasion assay, $1 \times 10^{4}$ Hep3B or SMMC-7721 cells were plated on chambers pre-coated with $20 \mu \mathrm{g}$ Matrigel. In these two assays, the cells were plated in DMEM medium without serum in the upper chamber, and medium containing $10 \%$ fetal bovine serum in the lower chamber served as a chemoattractant. After $24 \mathrm{~h}$, cotton swabs removed the cells that did not migrate or invade through the pores. The inserts were fixed with $4 \%$ paraformaldehyde (Sangon, Shanghai, China) (30 min at room temperature), stained with $0.1 \%$ crystal violet (Beyotime, Haimen, Jiangsu, China) (30 min at room temperature) and washed with PBS (room temperature). Five random fields for each insert were counted under an inverted microscope at x100 magnification (Olympus Corporation, Tokyo, Japan). 
A

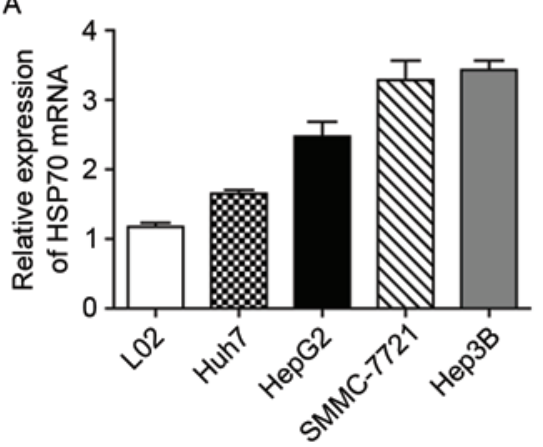

B

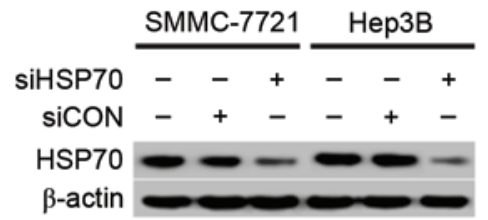

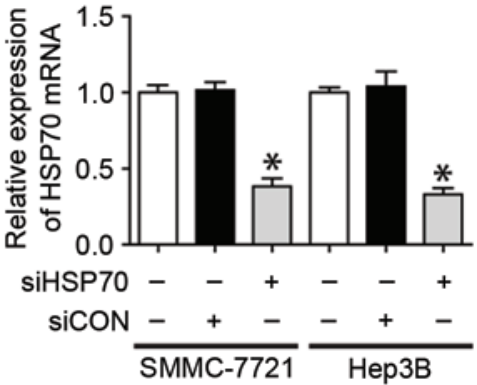

Figure 1. HSP70 expression in HCC cell lines and siRNA knockdown of HSP70 expression. (A) qPCR revealed that HSP70 mRNA was expressed in L02 normal hepatocytes and four HCC cell lines, including Huh7, HepG2, SMMC-7721 and Hep3B. (B) The western blotting (left) and qPCR (right) results indicate HSP70 expression in SMMC-7721 and Hep3B cells following various treatments, including HSP70-siRNA, siCON and no treatment. $\beta$-actin served as a loading control. All data are representative of three independent experiments. ${ }^{*} \mathrm{P}<0.05$ vs. siHSP70. HSP70, heat shock protein 70 ; HCC, hepatocellular carcinoma; si, small interfering; qPCR, quantitative polymerase chain reaction; $\mathrm{CON}$, control.

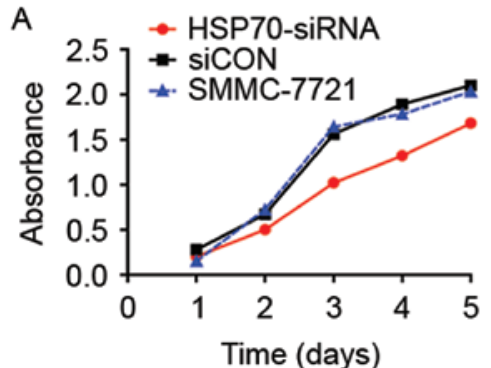

B

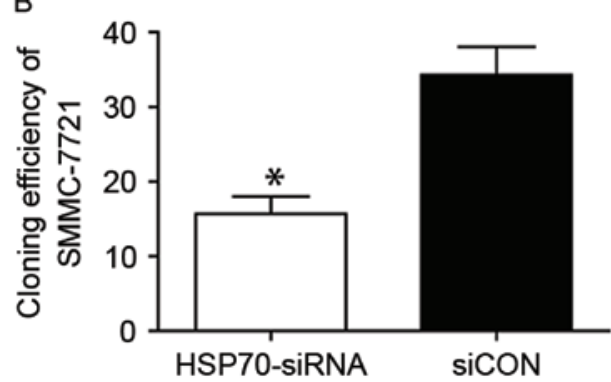

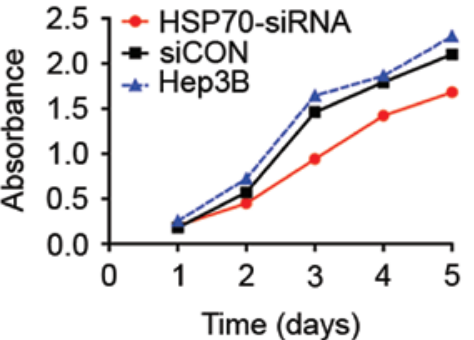

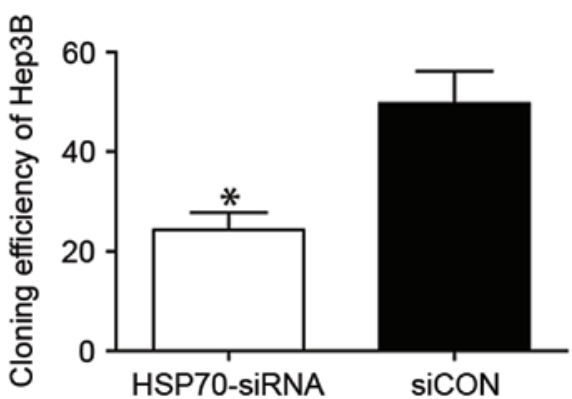

Figure 2. Proliferation and clonogenic assays were performed in SMMC-7721 and Hep3B cells through HSP70 knockdown. (A) The proliferation ability was significantly decreased in the HSP70-siRNA group, as compared with in the siCON and untreated groups (left graph for the SMMC-7721 cell line; right graph for the Hep3B cell line), particularly from the 3rd to the 5th day $(\mathrm{P}<0.05)$. (B) The clonogenic assay results (left graph for the SMMC-7721 cell line; right graph for the Hep3B cell line) demonstrated that the clone efficiency was markedly low in HSP70-siRNA when compared with the siCON group (P<0.05). A total of three individual experiments were performed. Results are expressed as the means \pm standard deviation. ${ }^{*} \mathrm{P}<0.05$ vs. siHSP70. HSP70, heat shock protein 70 ; si, small interfering; CON, control.

Statistical analysis. All statistical analyses were performed using SPSS v18.0 (SPSS Inc., Chicago, IL, USA). The results are presented as the means \pm standard deviation, and statistical analysis was performed using the unpaired Student's t-test for two groups and one-way analysis of variance for more than two groups, followed by Dunnett's Test for multiple comparisons. $\mathrm{P}<0.05$ was considered to indicate a statistically significant difference. At least three replicates were performed for each experiment.

\section{Results}

Targeted HSP70 knockdown in HCC cells by siRNA. To demonstrate the expression of HSP70 in cell lines, normal hepatocyte
L02 and four HCC cell lines (Huh7, HepG2, SMMC-7721 and Hep3B) were used. In contrast to normal L02 hepatocytes, the four HCC cell lines exhibited greater expression of HSP70 (Fig. 1A), suggesting that HSP70 may be involved in hepatocarcinogenesis. Subsequently, to elucidate the role of HSP70 in hepatocarcinogenesis, the effect of HSP70 knockdown on HCC cell growth following transfecting HCC cells with HSP70-siRNA or siCON was examined. In the present study, two HCC cell lines (SMMC-7721 and Hep3B) were selected as the cell models, as they expressed higher levels of HSP70 when compared with the other two cell lines. The results of the western blotting and qPCR demonstrated that HSP70-siRNA may effectively suppress the protein and mRNA levels of HSP70 in the two examined cell lines (Fig. 1B and C). 
HSP70 knockdown affects the proliferation ability of HCC cells. The biological role of HSP70 in the growth of HCC cells was subsequently investigated. The proliferative capacity of SMMC-7721 (Fig. 2A, left) and Hep3B (Fig. 2A, right) cells following HSP70 knockdown decreased markedly when compared with that of corresponding siCON-transfected control cells, particularly from day $3-5$, as detected using a CCK-8. Furthermore, the cloning efficiency in the siCON group was significantly greater compared with that in HSP70-siRNA groups of SMMC-7721 (Fig. 2B, left; P<0.05) and Hep3B (Fig. 2B, left; $\mathrm{P}<0.05$ ). Therefore, transfection with HSP70-siRNA markedly reduced the proliferative ability of the two HCC cell lines, which is concordant with the aforementioned CCK- 8 assay results.

HSP70 expression regulates the distribution of the cell cycle in HCC cells. To further understand the mechanism underlying HSP70-knockdown-induced cell growth inhibition, flow cytometry was performed to examine the cell cycle of SMMC-7721 and Hep3B cells transfected with HSP70-siRNA or siCON for $48 \mathrm{~h}$. The proportion of the two cell lines treated with HSP70-siRNA in the $\mathrm{G}_{0} / \mathrm{G}_{1}$ stage evidently increased, while those in the $S$ and $G_{2}$ stages markedly decreased with respect to the siCON and untreated groups. In addition, the cell cycle distribution of HCC cells in the siCON and the untreated group was similar (Fig. $3 \mathrm{~A}$ and $\mathrm{B} ; \mathrm{P}<0.05$ ), and no significant difference was observed. These results suggested that the growth inhibition induced by HSP70 downregulation is mediated by cell cycle arrest at the $\mathrm{G}_{1} / \mathrm{S}$ phase in $\mathrm{HCC}$ cells. Additionally, cyclin D1 and $\mathrm{p} 27^{\mathrm{Kipl}}$, two cell cycle-associated molecules, were used to evaluate the differences in the cell cycle distribution of the two cells. Cyclin D1 expression was notably decreased, whereas $227^{\text {Kipl }}$ expression was markedly increased, in the HSP70-siRNA group, as compared with in the siCON and untreated groups (Fig. 3C).

HSP70 contributes to migration and invasion in HCC cells. As recurrence and metastasis are two main factors contributing to the poor prognosis of $\mathrm{HCC}$, the migratory and invasive ability of SMMC-7721 and Hep3B cells was examined. The HSP70-siRNA of SMMC-7721 (Fig. 4A) and Hep3B (Fig. 4B) cells significantly inhibited migration compared with control groups after $48 \mathrm{~h}$. In the Transwell migration and invasion assay (Fig. 4C and D), HSP70 knockdown decreased cell migration in the two tested cell lines, compared with in the siCON and control groups. Furthermore, there a higher number of invaded cells in the siCON and control groups, as compared with those in the HSP70-siRNA group. Consistently, knockdown of HSP70 inhibited cell migration and invasion. Thus, the data indicate that an overexpression of HSP70 promotes migration and invasive capabilities in vitro, and a reduction of HSP70 correspondingly attenuates HCC cell aggression.

\section{Discussion}

HSPs were initially identified as proteins that are significantly induced by heat shock and other chemical and physical stresses (15). In previous years, HSPs were demonstrated to be overexpressed in a wide range of human cancer types, including HCC (16), and were implicated in tumor cell proliferation, differentiation, invasion and metastasis (17). HSP70 is a major stress-inducible heat shock protein, which has also been revealed to be highly elevated in different types of cancer (18), suggesting that it may also serve a role in carcinogenesis. As for the role of HSP70 in regulating the biological activities of $\mathrm{HCC}$, there is only a small quantity of relevant data available at present. Therefore, a series of expression and function assays were performed in order to identify the vital role of HSP70, and to explore the function of HSP70 in HCC.

In the present study, as demonstrated by qPCR, HSP70 expression was higher in the four types of HCC cell lines compared with in the normal L02 cells, which is in accordance with in HCC tissues specimens (19) and other types of malignant tumors, including lung cancer (20), breast cancer (21) and colorectal carcinoma (22). Subsequently, SMMC-7721 and Hep3B were selected for additional study as HSP70 expression was higher in these two HCC cell lines, compared with the other two HCC cell lines. As western blotting and qPCR revealed, HSP70-siRNA markedly reduced HSP70 expression in the SMMC-7721 and Hep3B cells.

Next, the proliferation assay indicated that transfection with HSP70-siRNA markedly decreased the proliferation potential of SMMC-7721 and Hep3B cells when compared with the siCON and untreated groups. A potential explanation is that the knockdown of HSP70 may inhibit Wnt/ $/$-catenin signaling, which serves a pivotal role in the progression of HCC $(23,24)$. This difference was significant, particularly from days 3-5 following transfection; this is concordant with the western blot analysis results, as the knockdown of HSP70 expression was most notable following transfection for $48 \mathrm{~h}$. Furthermore, the cloning efficiency in the HSP70-siRNA group was markedly lower compared with in the siCON group, which was also in accordance with the CCK-8 assay results. Therefore, knockdown of HSP70 inhibited the proliferation ability of the two HCC cell lines.

Following this, flow cytometry assays demonstrated that the growth inhibitory effect of HSP70 was caused by cell cycle arrest at $\mathrm{G}_{1} / \mathrm{S}$ phase. The expression of the cell cycle regulator cyclin D1 was markedly downregulated, while the expression of $\mathrm{p} 27^{\mathrm{Kipl}}$ was upregulated. Cyclin D1 is considered to be involved in altering cell cycle progression and is a downstream target of Wnt/ $\beta$-catenin signaling (25). It is frequently observed in a variety of tumor types, and may contribute to tumorigenesis $(26,27)$. In addition, $\mathrm{p} 27^{\mathrm{Kip1}}$, a cell-cycle inhibitory molecule, suppresses the catalytic activity of cyclin D-cyclin-dependent kinase 4 (28), and is overexpressed in the very early stages of HCC development (29). Ray et al (28) demonstrated that HSP70 is strictly regulated during the cell cycle and that levels of HSP70 mRNA rapidly increase 10-15-fold upon entry into the $\mathrm{S}$ phase, and then decline by the late $S$ and $G_{2}$ phase. Therefore, the knockdown of HSP70 may inhibit the Wnt/ $\beta$-catenin signaling pathway, contributing to the downregulation of target molecule Cyclin D1 and an inhibition of the cell cycle. In the present study, the population of the two HCC cell lines (SMMC-7721 and Hep3B) treated with HSP70-siRNA in $\mathrm{G}_{0} / \mathrm{G}_{1}$ stage markedly increased, while those in $\mathrm{S}$ and $\mathrm{G}_{2} / \mathrm{M}$ stage markedly decreased compared with the siCON and untreated groups, which indicated that the cell cycle was activated by HSP70 and inhibited by HSP70-siRNA at the $\mathrm{G}_{1} / \mathrm{S}$ stage. 
$\mathbf{A}$

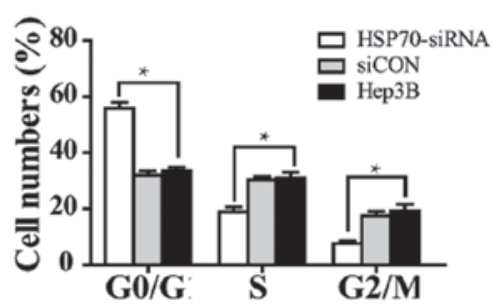

B

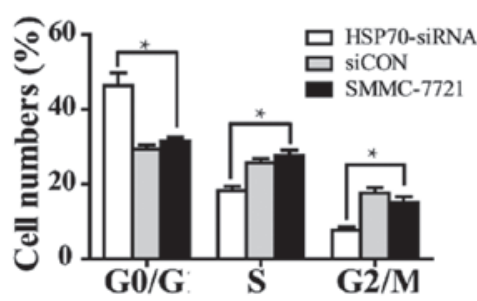

C

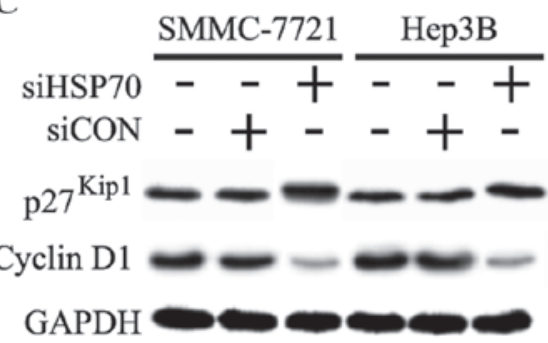

Figure 3. The effect on the cell cycle distribution following various treatments in SMMC-7721 and Hep3B cells with HSP70 knockdown. (A) Cell cycle distribution of Hep3B cells following various treatments. (B) Cell cycle distribution of SMMC-7721 cells with various treatments. Notably, the number of cells in the $\mathrm{G}_{0} / \mathrm{G}_{1}$ stage was markedly higher in the HSP70-siRNA group, compared with in the siCON and untreated groups. (C) Western blot results revealed that cyclin D1 and $\mathrm{p} 27^{\mathrm{Kipl}}$ expression varied with different treatments. GAPDH served as the loading control. All data are representative of $\geq 3$ independent experiments. HSP70, heat shock protein 70; si, small interfering; CON, control; p27 ${ }^{\mathrm{Kip} 1}$, cyclin-dependent kinase inhibitor 1B.

A

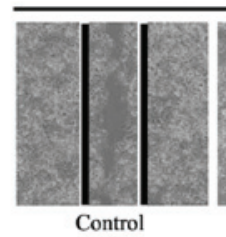

C

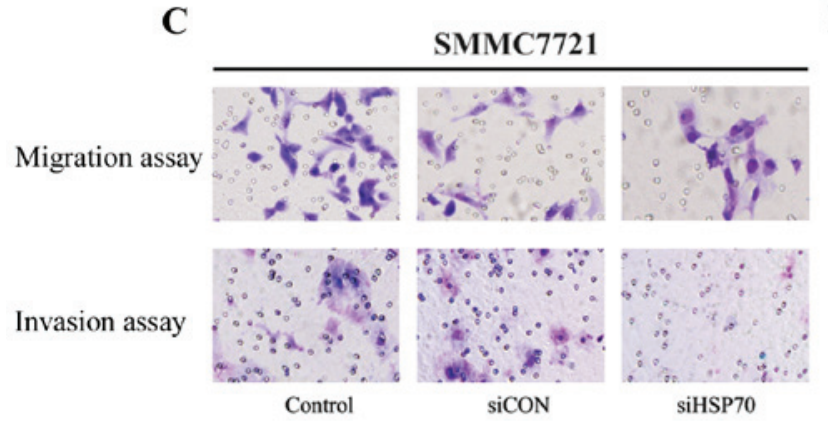

SMMC7721

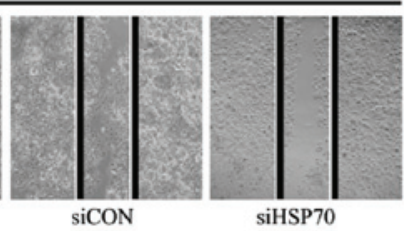

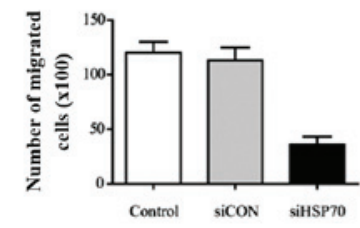

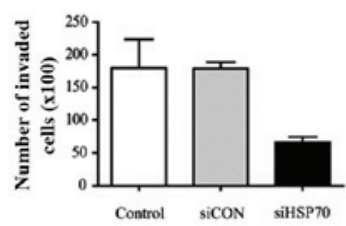

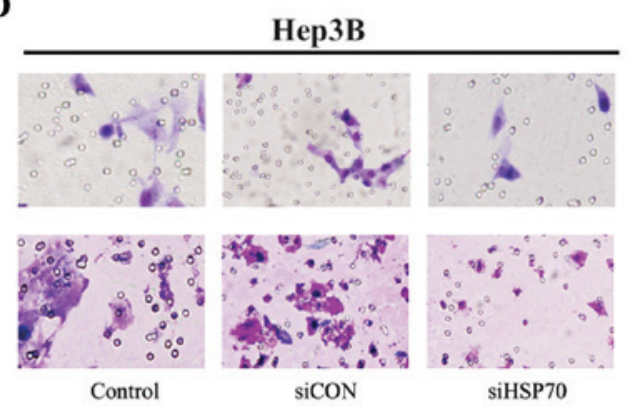

B

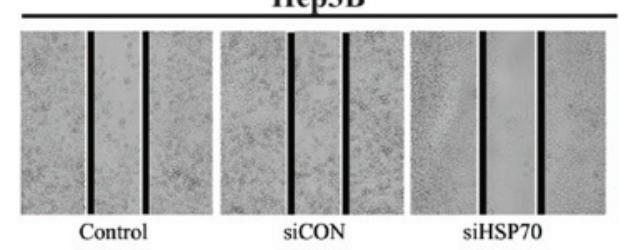

Hep3B
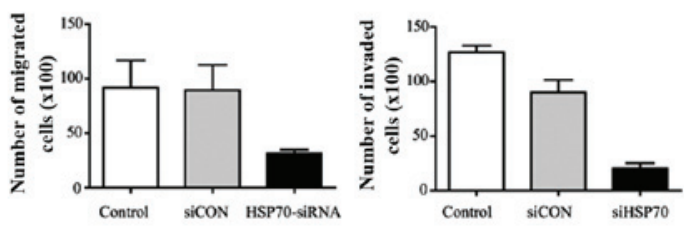

Figure 4. Inhibition of migration and invasion in SMMC-7721 and Hep3B cells with HSP70 knockdown. (A) Wound healing assay results demonstrated the inhibitory effect of siHSP70 on the migration of SMMC-7721 cells at $48 \mathrm{~h}$ following wounding, compared with the siCON and control cells. (B) The wound-healing assay revealed the marked inhibitory effect of siHSP70 on the migration of Hep3B cells at $48 \mathrm{~h}$ following wounding, compared with siCON and control cells. (C) Representative images of migration (upper panel) and invasion (middle panel) assays for the inhibitory effect of siHSP70 on the invasion ability of SMMC-7721 cells. The lower bar panel depicts the mean number of migrated and invaded cells at $48 \mathrm{~h}$. "P<0.05. (Magnification, x100), (D) Representative images of migration (upper panel) and invasion (middle panel) assay results for the inhibitory effect of siHSP70 on the invasive ability of Hep3B cells. The lower bar graph indicates the mean number of migrated and invaded cells at $48 \mathrm{~h}$. " $\mathrm{P}<0.05$. (magnification, x100). si, small interfering; HSP70, heat shock protein 70 ; CON, control.

Invasion and metastasis are two of the principal hallmarks of cancer and are associated with malignant cancer-associated mortality, particularly for HCC. The long-term survival of patients with HCC following curative resection retains the obstacle of a high recurrence rate, which is primarily due to the spread of intrahepatic metastases (30). Therefore, the identification of metastatic factors and an understanding of the underlying molecular pathways that are involved in the progression of metastasis are critical. Previous studies have demonstrated that HSPs serve a key role in the invasion and metastasis of various tumors, thereby opening a novel avenue for investigating the molecular mechanisms of tumor progression and develop potential therapeutics (31). A number of studies have implicated HSP70 as an important regulator for multiple steps of metastasis in human cancer $(17,32,33)$. Fang et al (34) indicated that HSF1 was capable of promoting HCC cell migration and invasion by facilitating the expression and phosphorylation of HSP27. Hartmann et al (35) suggested that Hsp90 inhibition decreases the migration and invasion abilities of lung carcinoma and glioblastoma cell lines. In the present study, HSP70 knockdown was demonstrated to markedly inhibit HCC cell invasion and metastasis in the two cell lines; however, the potential underlying mechanism requires additional exploration. 
In conclusion, the present study provides an early analysis of the pivotal role of HSP70 in the tumorigenesis and progression of HCC. These data demonstrate that the knockdown of HSP70 expression leads to decreasing proliferative ability, inhibition of the cell cycle and the suppression of invasive and metastatic capacity in two HCC cell lines with relatively lower HSP70 expression levels. Taking these results into consideration, along with those from previous studies, the observations from the present study suggest that HSP70 may be a promising target for future therapy for HCC.

\section{Acknowledgements}

The present study was supported by a grant from the International Cooperative Projects of Hainan Province (grant no. KJHZ2014-14).

\section{References}

1. Llovet JM, Ricci S, Mazzaferro V, Hilgard P, Gane E, Blanc JF, de Oliveira AC, Santoro A, Raoul JL, Forner A, et al: Sorafenib in advanced hepatocellular carcinoma. N Engl J Med 359: 378-390, 2008.

2. Yin J, Zhu JM and Shen XZ: The role and therapeutic implications of RING-finger E3 ubiquitin ligases in hepatocellular carcinoma. Int J Cancer 136: 249-257, 2015.

3. Hanahan D and Weinberg RA: Hallmarks of cancer: The next generation. Cell 144: 646-674, 2011.

4. Yasui W, Sentani K, Sakamoto N, Anami K, Naito Y and Oue N: Molecular pathology of gastric cancer: Research and practice. Pathol Res Pract 207: 608-612, 2011.

5. Dawson MA and Kouzarides T: Cancer epigenetics: From mechanism to therapy. Cell 150: 12-27, 2012.

6. Farazi PA and DePinho RA: Hepatocellular carcinoma pathogenesis: From genes to environment. Nat Rev Cancer 6: 674-687, 2006.

7. Shi X, Zhu HR, Liu TT, Shen XZ and Zhu JM: The Hippo pathway in hepatocellular carcinoma: Non-coding RNAs in action. Cancer Lett 400: 175-182, 2017.

8. Mosser DD and Morimoto RI: Molecular chaperones and the stress of oncogenesis. Oncogene 23: 2907-2918, 2004.

9. Vargas-Roig LM, Fanelli MA, López LA, Gago FE, Tello O, Aznar JC and Ciocca DR: Heat shock proteins and cell proliferation in human breast cancer biopsy samples. Cancer Detect Prev 21: 441-451, 1997.

10. Lazaris AC, Theodoropoulos GE, Aroni K, Saetta A and Davaris PS: Immunohistochemical expression of C-myc oncogene, heat shock protein 70 and HLA-DR molecules in malignant cutaneous melanoma. Virchows Arch 426: 461-467, 1995.

11. Kaur J, Srivastava A and Ralhan R: Expression of 70-kDa heat shock protein in oral lesions: Marker of biological stress or pathogenicity. Oral Oncol 34: 496-501, 1998.

12. Syrigos KN, Harrington KJ, Karayiannakis AJ, Sekara E, Chatziyianni E, Syrigou EI and Waxman J: Clinical significance of heat shock protein-70 expression in bladder cancer. Urology 61 677-680, 2003

13. Udono $\mathrm{H}$ and Srivastava PK: Heat shock protein 70 -associated peptides elicit specific cancer immunity. J Exp Med 178: 1391-1396, 1993

14. Livak KJ and Schmittgen TD: Analysis of relative gene expression data using real-time quantitative PCR and the 2(-Delta Delta C(T)) Method. Methods 25: 402-408, 2001.

15. Lindquist $\mathrm{S}$ and Craig EA: The heat-shock proteins. Annu Rev Genet 22: 631-677, 1988.

16. Lim SO, Park SG, Yoo JH, Park YM, Kim HJ, Jang KT, Cho JW, Yoo BC, Jung GH and Park CK: Expression of heat shock proteins (HSP27, HSP60, HSP70, HSP90, GRP78, GRP94) in hepatitis B virus-related hepatocellular carcinomas and dysplastic nodules. World J Gastroenterol 11: 2072-2079, 2005.
17. Ciocca DR, Green S, Elledge RM, Clark GM, Pugh R, Ravdin P, Lew D, Martino S and Osborne CK: Heat shock proteins hsp27 and hsp70: Lack of correlation with response to tamoxifen and clinical course of disease in estrogen receptor-positive metastatic breast cancer (a Southwest Oncology Group Study). Clin Cancer Res 4: 1263-1266, 1998.

18. Nylandsted J, Brand K and Jäättelä M: Heat shock protein 70 is required for the survival of cancer cells. Ann N Y Acad Sci 926: $122-125,2000$

19. Murphy ME: The HSP70 family and cancer. Carcinogenesis 34: 1181-1188, 2013

20. Malusecka E, Zborek A, Krzyzowska-Gruca S and Krawczyk Z: Expression of heat shock proteins HSP70 and HSP27 in primary non-small cell lung carcinomas. An immunohistochemical study. Anticancer Res 21: 1015-1021, 2001

21. Lazaris ACh, Chatzigianni EB, Panoussopoulos D, Tzimas GN, Davaris PS and Golematis BCh: Proliferating cell nuclear antigen and heat shock protein 70 immunolocalization in invasive ductal breast cancer not otherwise specified. Breast Cancer Res Treat 43: 43-51, 1997.

22. Hwang TS, Han HS, Choi HK, Lee YJ, Kim YJ, Han MY and Park YM: Differential, stage-dependent expression of Hsp70, Hsp110 and Bcl-2 in colorectal cancer. J Gastroenterol Hepatol 18: 690-700, 2003.

23. Thompson MD and Monga SP: WNT/beta-catenin signaling in liver health and disease. Hepatology 45: 1298-1305, 2007.

24. Wands JR and Kim M: WNT/beta-catenin signaling and hepatocellular carcinoma. Hepatology 60: 452-454, 2014

25. Botrugno OA, Fayard E, Annicotte JS, Haby C, Brennan T, Wendling O, Tanaka T, Kodama T, Thomas W, Auwerx J and Schoonjans K: Synergy between LRH-1 and beta-catenin induces G1 cyclin-mediated cell proliferation. Mol Cell 15: 499-509, 2004

26. Tetsu $\mathrm{O}$ and McCormick F: Beta-catenin regulates expression of cyclin D1 in colon carcinoma cells. Nature 398: 422-426, 1999.

27. Buckley MF, Sweeney KJ, Hamilton JA, Sini RL, Manning DL, Nicholson RI, deFazio A, Watts CK, Musgrove EA and Sutherland RL: Expression and amplification of cyclin genes in human breast cancer. Oncogene 8: 2127-2133, 1993.

28. Ray A, James MK, Larochelle S, Fisher RP and Blain SW: p27Kip1 inhibits cyclin D-cyclin-dependent kinase 4 by two independent modes. Mol Cell Biol 29: 986-999, 2009.

29. Yachida S, Sakamoto M, Imaida K, Yokohira M, Saoo K, Okano K, Wakabayashi H, Maeta H and Suzuki Y: p27(Kip1) is overexpressed in very early stages of hepatocarcinogenesis. Cancer Sci 99: 2152-2159, 2008.

30. Poon RT, Fan ST, Ng IO, Lo CM, Liu CL and Wong J: Different risk factors and prognosis for early and late intrahepatic recurrence after resection of hepatocellular carcinoma. Cancer 89: 500-507, 2000

31. Calderwood SK, Khaleque MA, Sawyer DB and Ciocca DR: Heat shock proteins in cancer: Chaperones of tumorigenesis. Trends Biochem Sci 31: 164-172, 2006.

32. Karlsson R, Pedersen ED, Wang Z and Brakebusch C: Rho GTPase function in tumorigenesis. Biochim Biophys Acta 1796: 91-98, 2009.

33. Nikfarjam M, Muralidharan V, Su K, Malcontenti-Wilson C and Christophi C: Patterns of heat shock protein (HSP70) expression and Kupffer cell activity following thermal ablation of liver and colorectal liver metastases. Int J Hyperthermia 21: 319-332, 2005.

34. Fang F, Chang R and Yang L: Heat shock factor 1 promotes invasion and metastasis of hepatocellular carcinoma in vitro and in vivo. Cancer 118: 1782-1794, 2012.

35. Hartmann S, Günther N, Biehl M, Katzer A, Kuger S, Worschech E, Sukhorukov VL, Krohne G, Zimmermann H, Flentje M and Djuzenova CS: Hsp90 inhibition by NVP-AUY922 and NVP-BEP800 decreases migration and invasion of irradiated normoxic and hypoxic tumor cell lines. Cancer Lett 331: 200-210, 2013. 